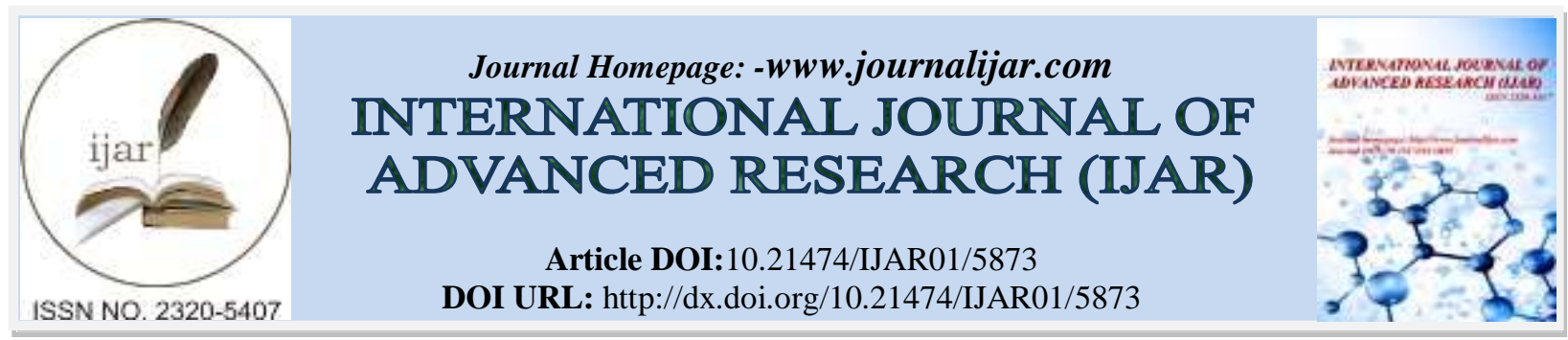

RESEARCH ARTICLE

\title{
SOMATOFORM DISORDERS TO SOMATIC SYMPTOM AND RELATED DISORDERS, AN OVERVIEW.
}

\author{
Dr. Kunjan Gupta ${ }^{1}$, Dr. Vipul Singh ${ }^{2}$, Dr. Saurabh Agarwal ${ }^{3}$ and Dr. Mohammad Yaseen ${ }^{4}$ \\ 1. Senior Resident in Department of Psychiatry, GSVM Medical College, Kanpur. \\ 2. Associate Professor in Psychiatry, Government Medical College, Kannauj. \\ 3. Assistant Professor in Medicine, GSVM Medical College, Kanpur. \\ 4. Non PG Junior Resident in Department of Psychiatry, GSVM Medical College, Kanpur.
}

\section{Manuscript Info}

Manuscript History

Received: 15 September 2017

Final Accepted: 17 October 2017

Published: November 2017

Key words:-

Somatic Symptom and Related

Disorders.

\section{Abstract}

The somatoform disorders are a group of psychiatric disorders that cause unexplained physical symptoms. In DSM-5, somatoform disorders are recognized under the term somatic symptom and related disorders, which include: somatic symptom disorder, illness anxiety disorder, conversion disorder, factitious disorder, psychological factors affecting other medical conditions, other specified somatic symptom and related disorder and unspecified somatic symptom and related disorder. These disorders are consistently under diagnosed and under-recognized which precludes effective treatment.

Copy Right, IJAR, 2017. All rights reserved.

\section{Introduction:-}

The somatoform disorders are a group of psychiatric disorders in which patients present with a myriad of clinically significant but unexplained physical symptoms (1). In somatoform disorders, physical symptoms suggest a physical disorder, but there are no demonstrable organic findings and there is strong evidence for link to psychological factors or conflicts.

Somatization is a poorly understood "blind spot" of Medicine (2). "Somatization" term was introduced by Stekl to denote "the expression of emotional distress as bodily symptoms. It was the St Louis group Perley and Guze (3) who described the Briquet's syndrome as "chronic multiple somatic symptoms, with no identifiable organic cause" (Table.1) (4).

Prior to 1800 , physicians did not conduct clinical evaluations and could not distinguish somatic from psychogenic illness. Sigmund Freud was the principal theoretician to bring psyche and soma together (5). He demonstrated the importance of the emotions in producing mental disturbances and somatic disorders. Using Freud insight, a number of workers in early decades of 20th century tried to expand the understanding of the inter-relationship of psyche and soma. In the 20th century, somatization symptoms changed from predominantly neurological to other symptoms such as fatigue and chronic pain.

The practice of psychosomatic medicine has evolved considerably since its early clinical origins. In large part this evolution has occurred as result of the increased complexity of medicine, the increased understanding of the relationship of medical illness to psychiatric illness, and the greater appreciation of the mind and body as one. 
Somatoform disorder in children and adolescents still remain one of the most neglected areas. Most pain and undifferentiated disorders start in childhood or early adolescence. Somatoform disorders among children and adolescents cause impairment in educational and social functioning and generate a great deal of psychosocial distress. (6)

\section{Classification:-}

According to ICD 10 Diagnostic criteria (7), Somatoform disorders include:

F45.0 - Somatization disorder

F45.1 - Undifferentiated somatoform disorder

F45.2 - Hypochondriacal disorder

F45.3 - Somatoform autonomic dysfunction

F45.4 - Persistent somatoform pain dysfunction

F45.8 - Other somatoform disorders

F45.9 - Somatoform disorder, unspecified

In DSM III, the term somatoform disorder was introduced for "a group of disorders characterized by physical symptoms, not explained by organic factors". According to DSM IV, in somatoform disorders the common feature is "presence of physical symptoms which suggest a general medical condition and are not fully explained by general medical condition, substance use or another mental disorder". This disorder also produces clinically significant distress or impairment in social, occupational or other important areas of functioning (8).

In DSM-5 (2013) Somatoform disorders are recognized under the term Somatic Symptom and Related

Disorders:-

These include:-

1. Somatic symptom disorder

2. Illness anxiety disorder.

3. Conversion disorder(functional neurological symptom disorder)

4. Factitious disorder

5. Psycological factors affecting other medical conditions

6. Other specified somatic symptom and related disorder.

7. Unspecified somatic symptom and related disorder.

\section{Somatic Symptom Disorder:-}

Patient is preoccupied with false belief that they have a serious disease, based on their misinterpretation of physical signs and sensations. The belief must last at least 6 months, despite the absence of pathological findings on medical and neurological examination. Onset of symptoms may occur at any age but the disorder most commonly appears in persons $20-30$ years of age (5).

Course is usually episodic; episodes last from months to years. A good prognosis is associated with high socioeconomic status, treatment responsive anxiety or depression, sudden onset of symptoms and absence of personality disorder and absence of related non-psychiatric medical condition.

\section{Illness Anxiety Disorder:-}

Patient is preoccupied with the false belief that they have or will develop a serious disease and there are few if any physical signs or symptoms. The belief must last at least 6 months, and there are no pathological findings on medical or neurological examination. One might expect the disorder to be diagnosed more frequently in older rather than younger persons (5). Course is episodic; may last from months to years.

\section{Conversion Disorder (Functional Neurological Symptom Disorder):-}

DSM -5 limits the diagnosis of conversion disorders to those symptoms that affect a voluntary motor or sensory functions i.e. neurological symptom. Clinical findings provide evidence of incompatibility between the symptom and recognized neurological or medical condition.

The onset of conversion disorder is usually acute. One of the major problems in diagnosing conversion disorder is the difficulty of definitively ruling out a medical disorder. When symptoms suggest a conversion disorder onset in middle or old age, the probability of an occult neurological or other medical condition is high. Anxiety disorders 
especially panic disorder, and depressive disorders commonly co-occur with conversion disorder. Neurological or other medical condition commonly coexists with conversion disorder as well.

\section{Factitious Disorder:-}

DSM 5 Diagnostic criteria include falsification of physical or psychological signs or symptoms, or induction of injury or disease, associated with identified deception. The individual presents himself or herself to others as ill, impaired, or injured. The deceptive behavior is evident even in the absence of obvious external rewards.

Limited studies indicate that patients with factitious disorder may comprise $0.8-1 \%$ of psychiatric consultation patients (5). The course of factitious disorder is usually one of intermittent episodes.

\section{Symptoms:-}

$\begin{array}{ll}\begin{array}{ll}\text { Table 1:- Selected Symptoms of Somatization Disorder } \\ \text { Gastrointestinal (two) }\end{array} & \text { Pseudoneurologic (one) } \\ \text { Bloating } & \text { Amnesia } \\ \text { Diarrhea } & \text { Aphonia } \\ \text { Food intolerance } & \text { Blindness } \\ \text { Nausea } & \text { Difficulty swallowing } \\ \text { Vomiting } & \text { Double vision } \\ \text { Pain (four) } & \text { Impaired coordination } \\ \text { Abdominal } & \text { Loss of consciousness } \\ \text { Back } & \text { Paralysis } \\ \text { Chest } & \text { Paresthesias } \\ \text { Dysmenorrhea } & \text { Urinary retention } \\ \text { Dysuria } & \text { Sexual (one) } \\ \text { Extremity } & \text { Ejaculatory dysfunction } \\ \text { Head } & \text { Erectile dysfunction } \\ \text { Joint } & \text { Hyperemesis of pregnancy } \\ \text { Rectal } & \text { Irregular menses } \\ & \text { Menorrhagia } \\ & \text { Sexual indifference }\end{array}$

Note:- Numbers in parenthesis refer to the number of symptoms in each category required for the diagnosis of somatization disorder (in addition to other criteria). (4)

\section{Etiology:-}

Little is known about the causes of the somatoform disorders. Etiology includes patho-physiological mechanisms, genetic and developmental factors, cognitive theories, personality characteristics, psychodynamic factors, sexual and physical abuse, socio-cultural factors, gender and iatrogenesis (8).

\section{Assessment and Diagnosis of Somatoform Disorders:-}

The challenge in working with somatoform disorders in the primary care setting is to simultaneously exclude medical causes for physical symptoms while considering a mental health diagnosis. There are no specific physical examination findings or laboratory data that are helpful in confirming these disorders. Clinical diagnostic tools have been used to assist in the diagnosis of somatoform disorders (11). One screening tool for psychiatric disorders that is used in primary care settings is the Patient Health Questionnaire (PHQ) (12).

Building an alliance with the patient, collaborating with referral source, reviewing the medical records, gathering collateral information from others, performing physical and neurological examination and obtaining a complete psychiatric history, including past history, family history, developmental history, a full mental status examination including a cognitive examination are the key to the diagnosis. 


\section{Neuroimaging Evidence:-}

A recent review of the cognitive-affective neuroscience of Somatization disorder suggested that catastrophization in patients with Somatization disorders tends to present a greater vulnerability to pain. The relevant brain regions include the dorsolateral prefrontal, insular, rostral anterior cingulate, premotor, and parietal cortices $(13,14)$.

\section{Management:-}

The management of somatoform disorders is generally a complex and lengthy process. Consider and discuss the possibility of the disorder with the patient early in the work-up, after ruling out organic pathology as the primary etiology for the symptoms, to confirm the psychiatric diagnosis. The delivery of the diagnosis may be the most important treatment step. A patient with medically unexplained somatic symptoms is often at a loss to understand the why and how of his symptoms.

Also psychiatric disorders rarely exist in isolation, and somatoform disorders are no exception. Clinically significant depressive disorder, anxiety disorder, personality disorder, and substance abuse disorder often coexist with somatoform disorders and should be treated concurrently using appropriate modalities (15)

\section{Adopting 'caring rather than curing as the goal' is useful:-}

Practice Management Strategies for Somatoform Disorders (16, 17, 18, 19)

1. Accept that patients can have distressing, real physical symptoms and medical conditions with coexisting psychiatric disturbance without malingering or feigning symptoms.

2. Consider and discuss the possibility of somatoform disorders with the patient early in the work-up, if suspected, and make a psychiatric diagnosis only when all criteria are met

3. Once the diagnosis is confirmed, provide patient education on the individual disorder using empathy and avoiding confrontation

4. Avoid unnecessary medical tests and specialty referrals, and be cautious when pursuing new symptoms with new tests and referrals

5. Focus treatment on function, not symptom, and on management of the disorder, not cure

6. Address lifestyle modifications and stress reduction, and include the patient's family if appropriate and possible

7. Treat comorbid psychiatric disorders with appropriate interventions

8. $\quad$ Use medications sparingly and always for an identified cause

9. Schedule regular, brief follow-up office visits with the patient (five minutes each month may be sufficient) to provide attention and reassurance while limiting frequent telephone calls and "urgent" visits

10. Collaborate with mental health professionals as necessary to assist with the initial diagnosis or to provide treatment

Specific treatment models like Pharmacotherapy, Behavior treatments including Cognitive therapy and Cognitive Behavior Therapy, Dynamic psychotherapy, Group therapy, Individual Insight-Oriented Psychotherapy, Behavior Therapy, Hypnosis, Marital Therapy, Family Therapy, Physical and Relaxation Therapies. To date, Cognitive Behavioral Therapy (CBT) is the best established treatment for a variety of somatoform disorders $(20,21,22)$. CBT aims to help patients realize, that their ailments are not catastrophic and to enable them to gradually return to activities they were previously engaged in, without fear of "worsening their symptoms".

\section{Conclusion:-}

Somatoform disorders are extremely common in primary care settings. Up to 50 percent of primary care patients present with physical symptoms that cannot be explained by a general medical condition. Some of these patients meet criteria for somatoform disorders $(23,24)$. Although most do not meet the strict psychiatric diagnostic criteria for one of the somatoform disorders, they can be referred to as having "somatic preoccupation," a subthreshold presentation of somatoform disorders that can also cause patients distress and require intervention. 
These patients continue to present with new set of symptoms in every visit, or persist with the same complaints and the investigations continue not to reveal anything significant, with the result that the initial interest and enthusiasm on the part of physician gives way to frustration and helplessness. This can lead on to unpleasantness and loss of trust in the doctor-patient relationship.

Understanding the relationship between health anxiety and beliefs about diseases and ill health may provide better insight for the physician in empathizing with these patients who are very likely to elicit negative emotional responses from the therapist and other care takers.

Given that somatoform symptoms are associated with high impairment, healthcare costs and both physician and patient frustration, it is critical to improve early detection. The first step in improving patient care is to identify the current barriers which obstruct successful diagnosis to enable the design of targeted interventions (25).

Thus, the treatment success can be enhanced by discussing the possibility of a somatoform disorder with the patient early in the evaluation process, limiting unnecessary diagnostic and medical treatments, focusing on the management of the disorder rather than its cure, using appropriate medications and psychotherapy for comorbidities, maintaining a psycho educational and collaborative relationship with patients, and referring patients to mental health professionals when appropriate.

\section{References:-}

1. OliverOyama, PhD, MHS, PA-C; Catherine Paltoo, MD, MS; and Julian Greengold, MD Somatoform Disorders American Family Physician, November 1, 2007 Volume 76, Number 9.

2. Quill TE. Somatization Disorder- one of medicine's blind spots. JAMA. 1985;254:3075-9.

3. Perley MJ, Guze SB. Hysteria - the stability and usefulness of clinical criteria. NEngl J Med. 1962;266:421-6.

4. Diagnostic and Statistical Manual of Mental Disorders. 4th ed. rev.: American Psychiatric Association, 2000.

5. 5)Benjamin James Sadock,M.D;Virginia Alcott Sadock,M.D;PedroRuiz,M.D; Kaplan and Sadock, Synopsis Of Psychiatry, eleventh edition. Chapter 13,Psychosomatic medicine.page no.465-496

6. Satyakammohapatra, Sardar J.K.Deo, Ashirbadsatapathy, NeelmadhavRath, Somatoform disorders in children and adolescents. German Journal of Psychiatry2014; 17(1): 19-24

7. The ICD - 10 Classification of Mental and Behavioral disorder; clinical descriptions and diagnostic guidelines, WHO,geneva,edition 2007.

8. Roy Abraham Kallivayalil and Varghese P. Punnoose ,Understanding and managing somatoform disorders: Making sense of non-sense Indian J Psychiatry. 2010 Jan; 52(Suppl1): S240-S245.

9. Diagnostic and Statistical Manual of Mental Disorders. 5th ed. Washington, D.C.: American Psychiatric Association.page309-327.

10. Barsky AJ. A comprehensive approach to the chronically somatizing patient. J Psychosom Res. 1998;45:301-6.

11. Chaturvedi SK, Desai G, Shaligram D. Somatoform disorders, somatization and abnormal illness behaviour. Int Rev Psychiatry 2006;18:75-80.

12. Spitzer RL, Williams JB, Kroenke K, Linzer M, deGruy FV III, Hahn SR,et al. Utility of a new procedure for diagnosing mental disorders in primary care. The PRIME-MD 1000 study. JAMA 1994;272:1749-56.

13. Stein DJ, Muller J (2008). "Cognitive-affective neuroscience of somatization disorder and functional somatic syndromes: reconceptualizing the triad of depressionanxiety-somatic symptoms". CNS Spectr. 13: 379-384.

14. Garcia-Campayoa, Javier; Fayed, Nicolas; Serrano-Blanco, Antoni; Roca, Miquel (2009). "Brain dysfunction behind functional symptoms: Neuroimaging and somatoform, conversive, and dissociative disorders.". Current Opinion in Psychiatry.22 (2): 224-231.

15. Servan-Schreiber D, Kolb NR, Tabas G. Somatizing patients: Part I.Practical diagnosis. Am Fam Physician 2000;61:1073-8.

16. Goldberg RJ, Novack DH, Gask L. The recognition and management of somatization. What is needed in primary care training. Psychosomatics 1992;33:55-61.

17. Walker EA, Unutzer J, Katon WJ. Understanding and caring for the distressed patient with multiple medically unexplained symptoms. J Am Board FamPract1998;11:347-56.

18. Gillette RD. Caring for frequent-visit patients. FamPractManag2003;10:57-62

19. Gillette RD. "Problem patients": a fresh look at an old vexation. FamPractManag2000;7:57-62.

20. Allen LA, Woolfolk RL, Escobar JI, Gara MA, Hamer RM "Cognitive-behavioral therapy for somatization disorder: a randomized controlled trial". Arch. Intern. Med. 166 (14): 1512-8. 
21. Mai F. "Somatization disorder: a practical review". Can J Psychiatry. 49 (10): 652-62.

22. Kroenke, Kurt. "Efficacy of treatment for somatoform disorders: A review of randomized controlled trials". Psychosomatic Medicine. 69 (9): 881-888.

23. Barsky AJ, Borus JF. Somatization and medicalization in the era of managed care. JAMA 1995;274:1931-4.

24. De Waal MW, Arnold IA, Eekhof JA, van Hemert AM. Somatoform disorders in general practice: prevalence, functional impairment and comorbidity with anxiety and depressive disorders. Br J Psychiatry 2004;184:470-6.

25. Alexandra M Murray, Anne Toussaint, Astrid Althaus, and Bernd Löwe. Barriers to the diagnosis of somatoform disorders in primary care: protocol for a systematic review of the current status, Systematic Reviews2013; 2:99. 